\title{
Valoração econômica da água na suplementação hídrica da agricultura brasileira em um modelo multissetorial de crescimento
}

\author{
Economic valuation of supplementary water in Brazilian crops in a \\ multisector growth model \\ Peterson Felipe Arias Santos ${ }^{1}$ (D), Humberto Francisco Silva Spolador ${ }^{1}$ (1) \\ "Escola Superior de Agricultura "Luiz de Queiroz" (ESALQ), Programa de Pós-graduação em Economia Aplicada, Universidade de \\ São Paulo (USP), Piracicaba (SP), Brasil. E-mails: peterson.arias@alumni.usp.br; hspolador@usp.br
}

Como citar: Santos, P. F. A., \& Spolador, H. F. S. (2022). Valoração econômica da água na suplementação hídrica da agricultura brasileira em um modelo multissetorial de crescimento. Revista de Economia e Sociologia Rural, 60(1) e238057. https://doi.org/10.1590/1806-9479.2021.238057

\begin{abstract}
Resumo: Apesar de possuir uma das maiores reservas de água doce do mundo, o Brasil apresenta uma elevada concentração deste recurso hídrico na região Norte, de modo que existe relativa escassez no atendimento de diferentes demandas, entre as quais a irrigação, abastecimento humano e uso industrial. Nesse sentido, têm surgido propostas e experiências de políticas de cobrança pelo uso da água que, inevitavelmente, passam pela atribuição de um valor econômico para ela. Os resultados empíricos deste artigo fornecem estimativas do valor econômico da água utilizada na suplementação hídrica de lavouras selecionadas, por meio da aplicação de um modelo multissetorial de crescimento, calibrado para o ano de 2005, utilizando uma matriz de contabilidade social com discriminação da remuneração da água, e um exercício de decomposição do crescimento. Os valores da água obtidos são expressos por meio de dois conceitos distintos existentes em uma perspectiva intertemporal: sua remuneração-sombra e seu preço-sombra. Os maiores valores de remuneração e preço-sombra estão no grupo de "outras lavouras" lavouras que não correspondem às produções de arroz e de cana-de-açúcar - do Centro-Sul brasileiro. Por outro lado, os menores valores foram obtidos para a cana-de-açúcar também no Centro-Sul, que é o maior demandante de água do país.
\end{abstract}

Palavras-chave: valor da água, agricultura brasileira, crescimento econômico, equilíbrio geral dinâmico.

\begin{abstract}
Despite having one of the largest freshwater reserves in the world, Brazil has a high concentration of this resource in the Northern region, thus, there is a relative shortage for meeting different demands, including irrigation, human consumption, and industrial use. In this sense, proposals and public policies for water use have emerged, which inevitably involve attributing an economic value to water use. The empirical findings of this study give estimations for the economic value of the water used for Brazilian crop supplementation, using a multisector growth model, calibrated for 2005 through a social accounting matrix with discrimination of water remuneration, and a growth accounting exercise. The water values obtained are expressed by two different concepts, defined in an intertemporal perspective: shadow rental value and shadow price. The highest shadow rental values and shadow prices values are in the group of "other crops" - crops that do not correspond to the rice or sugar cane production - in the Brazilian South-Central. On the other hand, the lowest values were obtained for sugar cane in the South-Central, which is the largest water user in the country.
\end{abstract}

Keywords: water value, Brazilian agriculture, economic growth, Dynamic general equilibrium.

\section{Introdução}

O Brasil possui uma extensão territorial da ordem de 8,5 milhões de quilômetros quadrados, divididos em doze grandes regiões hidrográficas com diferentes perfis de clima e disponibilidade hídrica, e que concentram, de maneira heterogênea, a população residente. Tal característica faz com que, a despeito de possuir cerca de 12\% da disponibilidade hídrica global (Brasil, 2008), 
exista relativa escassez de água, especialmente em áreas muito populosas e/ou em períodos de estiagens severas.

Neste contexto, embora constitua um tema politicamente controverso, iniciativas para que a água passe a ser tratada como recurso natural dotado de valor econômico e, portanto, sujeito a mecanismos de preços, têm surgido frente à necessidade do uso racional desta, além da obtenção de recursos para garantir o próprio acesso dos usuários aos corpos hídricos. Do ponto de vista microeconômico, a eficiência destas políticas e dos valores cobrados estaria associada à sua capacidade de equalizar o benefício marginal de uma unidade de água ao custo marginal de ofertá-la, conforme ocorreria em um mercado competitivo.

No setor agrícola, como não existe um mercado para água utilizada na suplementação hídrica das lavouras, de modo a estabelecer um preço eficiente, a cobrança pelo uso pelas agências reguladoras exige algum método científico para estimá-lo. Nesse sentido, Johansson (2005) sumarizou os métodos potenciais para aferir o valor da água nos níveis micro e macroeconômico, entre os quais modelos econométricos, de equilíbrio - geral e parcial -, além de abordagens empíricas como programação linear (PL), método residual, hedônico e outros.

O presente artigo insere-se no conjunto de trabalhos de abordagem macroeconômica, especificamente ao aplicar um modelo multissetorial de crescimento, que tem como uma de suas características tornar endógena a decisão de poupança das famílias ao estilo de Ramsey (1928). A partir deste modelo, o objetivo principal do trabalho é obter uma estimativa da remuneração e preço-sombra da água por $\mathrm{m}^{3}$ utilizada nas lavouras com suplementação hídrica no país. Justifica-se o emprego da metodologia pela relação teórica do preço-sombra de um recurso natural e o fluxo de remunerações-sombra, que, por sua vez, é fortemente influenciado pelo processo de acumulação de capital descrito nos modelos de crescimento econômico. Como observaram Roe \& Smith (2015), os valores dos recursos naturais e do capital físico passam a ser relativos e tendem a mover-se conjuntamente, sendo pertinente a análise conjunta de ambos no contexto dos modelos de crescimento econômico.

Além desta seção introdutória, este artigo está organizado da seguinte forma: a seção 2 contextualiza o uso de recursos hídricos no Brasil; a seção 3 apresenta as bases teóricas do modelo empírico empregado, bem como a base de dados utilizada para a calibração deste. Na seção 4 estão os resultados e respectiva discussão, seguidos, finalmente, da conclusão.

\section{O panorama do uso de recursos hídricos no Brasil}

Segundo dados da Agência Nacional de Águas [ANA] (2019), a irrigação foi responsável por $52,0 \%$ da retirada, e $68,4 \%$ do consumo de água dos corpos hídricos brasileiros. A vazão retirada, como sugere o nome, corresponde ao montante retirado dos corpos d'água para os respectivos usos, enquanto o conceito de vazão consumida representa a quantidade de água que, após utilizada, não retorna ao sistema hídrico. Como essa taxa de retorno é baixa na atividade agropecuária, as participações da irrigação e consumo animal no conceito de consumo são superiores às suas respectivas participações na vazão retirada.

A partir dos dados da ANA (Agência Nacional de Águas, 2019), pode-se concluir que a atividade irrigante retirou dos corpos d'água 34,2 bilhões do total de 65,8 bilhões de metros cúbicos de água ao longo do ano de 2017. Deve-se ressaltar que a água utilizada na suplementação hídrica das lavouras pode ter outras origens além dos corpos d'água, o que é especialmente importante no caso da cana-de-açúcar produzida no Brasil, em que parte significativa da água fornecida à lavoura advém da aplicação de vinhaça, um subproduto da produção de etanol e de elevado potencial poluente (Silva et al., 2007). 
Quanto ao aspecto regional, embora o país destinasse à irrigação 52,0\% da vazão total retirada, este valor é fortemente influenciado pelas regiões Sul e Nordeste, que, por razões distintas, têm grande dependência de regimes agrícolas irrigados. No caso do Sul, a rizicultura é altamente dependente da irrigação, especialmente por inundação, enquanto a região Nordeste apresenta baixa disponibilidade hídrica em grande parte do seu território, o que incentiva a adoção de técnicas de suplementação (Agência Nacional de Águas, 2019).

Na maior parte da região Norte, a elevada disponibilidade hídrica, o regime de chuvas e a estrutura produtiva tendem a não incentivar o uso de irrigação, com as exceções de Roraima e Tocantins. Ainda que possuam climas bastante distintos ${ }^{1}$, nesses dois estados viabilizou-se nas últimas décadas a produção de arroz irrigado, que tem demandado elevado grau de irrigação e grande participação relativa na retirada total dos dois estados.

Por fim, o Centro-Oeste possui níveis de precipitação favoráveis, na maior parte do ano, às lavouras ali presentes, dando segurança à produção de sequeiro. Contudo, tem ocorrido elevado crescimento do uso de irrigação nesta região, com particular importância do estado de Goiás, cuja área irrigada sextuplicou entre 1996 e 2015, especialmente por conta do uso de pivôs centrais e canhões aspersores (Agência Nacional de Águas, 2017).

Limitando a análise às lavouras, pode-se tratar da demanda por água bruta em si a partir das informações do Atlas irrigação: uso da água da água na agricultura irrigada (Agência Nacional de Águas, 2017). Embora, em termos totais, os valores divirjam de estimativas apresentadas pela agência reguladora mais recentemente², estes são os últimos dados públicos desagregados por cultura - no caso, as duas principais consumidoras e um agregado das demais culturas -, mas que, porém, consideram apenas a água obtida de corpos hídricos (Figura 1).
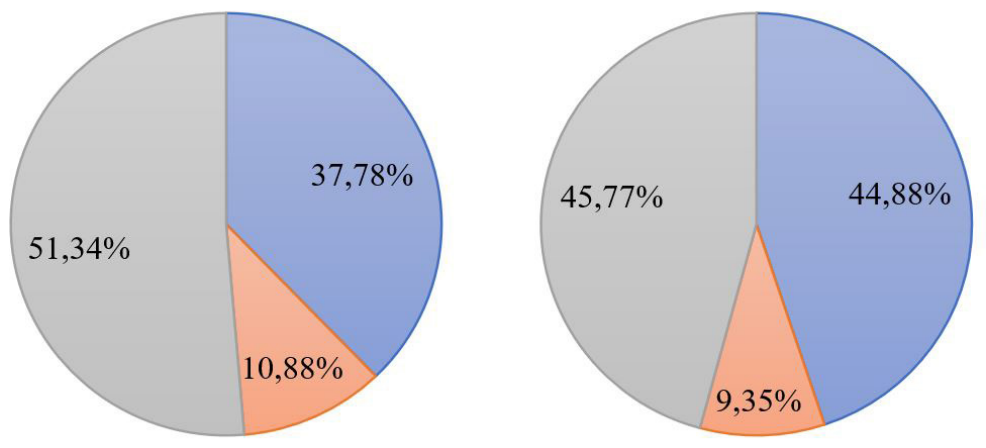

$\square$ Arroz Inundado $\square$ Cana-de-açúcar $\square$ Demais culturas

Figura 1. Composição relativa da retirada anual de água de corpos hídricos para fins de irrigação em 2015, por cultura. Fonte: Elaboração própria a partir de dados ANA (Agência Nacional de Águas, 2017).

Os dados referentes a 2015 evidenciam que as culturas da cana-de-açúcar e arroz respondem por cerca da metade do valor total das retiradas de água bruta no país. Acerca da produção

\footnotetext{
${ }^{1}$ Ver, por exemplo, o mapa produzido pelo Serviço Geológico do Brasil (2019). No caso do Tocantins, a localização de sua área por região climática difere substancialmente da região administrativa em que se encontra e, portanto, terá tratamento diferenciado no modelo empírico abordado adiante.

2 Ver ANA (Agência Nacional de Águas, 2019).
} 
rizícola, esta foi a primeira cultura amplamente irrigada no país na virada do século XIX para o XX (Agência Nacional de Águas, 2017), tendo até hoje grande dependência para com a irrigação. No caso da cana-de-açúcar, ressalta-se que, mesmo que os valores apresentados não considerem outras fontes de água utilizadas além de corpos hídricos, esta cultura tem participação em torno de $10 \%$ na demanda total, sendo necessário, portanto, especificá-la em análises sobre o tema.

Isto posto, os dados apresentados demonstram a importância de se considerar de maneira particular estas duas lavouras no modelo empírico implementado. Efetivamente, contudo, optou-se pela utilização de dados anteriores, referentes ao ano de 2006 , obtidos pelo projeto Desenvolvimento de Matriz de Coeficientes Técnicos para Recursos Hídricos no Brasile conduzido pela Fundação de Apoio à Universidade Federal de Viçosa (2011). Justifica-se a opção por esta base de dados para não restringir a origem deste recurso, ao contrário das estimativas mais recentes da Agência Nacional de Águas e, além disso, não haver disponibilidade suficiente de dados na edição de 2017 do Censo Agropecuário que permitisse a calibração do modelo dinâmico implementado para a análise deste artigo.

\section{Metodologia}

\subsection{O modelo econômico}

Esta seção descreve os aspectos relacionados ao modelo multissetorial de crescimento utilizado no que se refere ao seu desenvolvimento analítico, calibração e solução numérica. A notação considerada e a sequência de apresentação são semelhantes às de Roe et al. (2010) e, salvo expresso de outra forma, algumas convenções são adotadas: 1) letras maiúsculas indicam variáveis agregadas; 2 ) letras minúsculas apontam variáveis por trabalhador; 3 ) letras minúsculas com circunflexo ( $($ ) indicam variáveis por trabalhador efetivo; 4) o sinal gráfico til ( ) indica expressões algébricas em formas reduzidas.

Buscando minimizar ambiguidades na notação, adotou-se ainda uma convenção derivada da estrutura da matriz de contabilidade social (SAM), em que cada célula representa um pagamento da conta da coluna para a conta da linha. Na representação algébrica, os equivalentes às contas das colunas são identificados por sobrescritos, enquanto as contas das linhas por subscritos, identificando, quando for o caso, a região a que se refere. Dessa forma, por exemplo, $Y_{c, i}^{s, j}$ representaria a compra do bem $c$ produzido na região i realizada pelo setor $s$ da região ${ }_{j}$, ou seja, trata-se de consumo intermediário. Ademais, considerando esta quantidade física $Y_{c, i}^{s, j}$, o preço associado ao produto adquirido pode ser expresso apenas por $p_{c, i}$ sem explicitar os compradores, pois, sob concorrência perfeita, todos recebem o mesmo preço. Nem todas as variáveis, entretanto, possuem contrapartida na SAM, de modo que a notação é realizada por analogia, como ocorre, por exemplo, com o preço do capital, $p_{k^{\prime}}$ que indica o valor pago pelas firmas para ter o direito de propriedade sobre uma unidade deste ativo - diferente, portanto, de um mercado de aluguel de capital. Este tratamento busca facilitar a utilização de operadores baseados em índices e a concisão das expressões.

Cada bem é produzido por um único setor, de modo que as expressões "setor" e "produto" são equivalentes em diversos contextos, mas referindo-se, de maneira geral, a aspectos de oferta e demanda, respectivamente, fazendo necessário distingui-los na notação. Assim, visando maior clareza matemática, produtos e setores são indexados, nesta ordem, pelas letras ${ }_{c}$ e $s$ que assumem os números naturais entre 1 e 6 , com os conjuntos que representam sua totalidade dados por: 
$C=S=\{1,2,3,4,5,6\}$

Os setores considerados encontram-se no Quadro 1 com seus respectivos identificadores, de modo que, por exemplo, o preço do bem de serviços será identificado por $p_{6}$.

Quadro 1. Setores $(s)$ e produtos ( ) considerados no modelo e respectivos índices.

\begin{tabular}{|c|c|}
\hline Setor/Produto & Índices c, s \\
\hline Cana-de-açúcar & 1 \\
\hline Arroz em casca & 2 \\
\hline Outros produtos da lavoura & 3 \\
\hline Outros produtos da agropecuária & 4 \\
\hline Indústria & 5 \\
\hline Serviços & 6 \\
\hline
\end{tabular}

Fonte: Elaboração própria.

A desagregação setorial considerada é justificada pela importância da rizicultura e da produção canavieira na utilização de água para irrigação e pela disponibilidade de dados sobre os valores da produção agrícola associados aos dois regimes de produção possíveis (sequeiro e irrigado). Além disso, ao se manter apenas estas atividades desagregadas, há benefícios do ponto de vista computacional, dada a complexidade da solução numérica de modelos desta natureza, que incluem muitas variáveis dinamicamente endógenas.

Os setores industrial (s) e de serviços (6) são considerados nacionais, enquanto os setores de 1 a 4 são divididos em três regiões que, em grande medida, se sobrepõem às regiões administrativas brasileiras, com exceção do estado do Tocantins, que foi agregado à região denominada "NordesteTO", definida a seguir.

No detalhamento do modelo utilizado, dada a necessidade de definir relações intersetoriais e inter-regionais, é conveniente associar os conceitos de produto e setor-identificados por ${ }_{c} \mathrm{e}_{s}$, respectivamente - a dois índices distintos de região, neste caso as letras $i$ e ${ }_{j}$, respectivamente. Assim, sempre que um setor $s$ for regionalmente desagregado, este estará acompanhado por um índice $j$, enquanto o bem $c$ - caso seja regionalizado - será acompanhado pela letra ${ }_{i}$. Para fins de aplicação do modelo, a agregação regional considerada é exposta no Quadro 2, sendo o conjunto de regiões dado por $I=J=\{1,2,3\}$. Os nomes atribuídos às regiões do modelo buscam diferenciá-las das macrorregiões administrativas Norte e Nordeste.

Quadro 2. Agregação regional e indexação.

\begin{tabular}{ccc} 
Região do modelo & Índices i, j & Unidades Federativas do Brasil \\
Centro-Sul & 1 & $D F, E S, G O, M G, M S, M T, P R, R J, R S, S C, S P$ \\
NordesteTO & 2 & $A L, B A, C E, M A, P E, P I, R N, S E, T O$ \\
NorteExTO & 3 & $A C, A M, A P, P A, R O, R R$ \\
\hline
\end{tabular}

Fonte: Elaboração própria.

A agregação regional tem em conta, além da limitação operacional, características das atividades produtivas em termos de demandas hídricas resultantes de diferentes aspectos geográficos, especialmente a pluviometria. Admite-se, por exemplo, que a produção de arroz no Tocantins possui maior similaridade com aquela presente no estado do Maranhão do que com aquela existente no Pará. Dessa forma, o estado do Tocantins foi considerado em conjunto com o Nordeste brasileiro, formando, dentro do modelo, a região NordesteTO. 


\subsubsection{O ambiente econômico}

Inicialmente, a economia é dotada de $L(0)$ unidades de trabalho e $K(0)$ unidades de capital distribuídas entre todos os setores, além das dotações de água e terra em cada um dos setores que delas se utilizam nas distintas regiões. Os residentes são proprietários de todo o estoque de ativos, os serviços dos fatores de produção não são negociados internacionalmente, e suas respectivas remunerações são atribuídas às famílias que decidem o quanto consumir e investir em cada período.

Os bens produzidos pelos setores abertos ao comércio internacional são negociados a preços fixos, enquanto os preços da cana-de-açúcar e do bem de serviços são dinamicamente endógenos ao modelo. No caso do bem de serviços, este é considerado doméstico por hipótese do modelo original de Roe et al. (2010), enquanto a cana-de-açúcar não pode sofrer deslocamentos significativos (Bastos, 2013), sendo negociado em cada uma das regiões produtivas. Déficits ou superávits comerciais são negociados aos preços internacionais vigentes. Admite-se que o preço do bem industrial seja o numéraire.

A oferta de trabalho cresce a uma taxa constante $n$ e a produtividade aumentadora de trabalho à taxa constante $x$. Estabelecem-se, ainda, duas condições de sustentabilidade associadas às produtividades $\mathcal{B}(t)$ e $\Lambda(t)$ dos fatores fixos, terra e água, respectivamente: elas devem crescer a uma taxa que é a soma das taxas de crescimento da força de trabalho e do progresso técnico, ou seja:

$\eta_{T}=\eta_{H}=x+n$

em que $\eta_{T}$ e $\eta_{H}$ denotam as taxas de crescimento das produtividades associadas aos fatores fixos terra e água, respectivamente. Esta hipótese é compartilhada por uma série de trabalhos derivados do modelo originalmente desenvolvido por Roe et al. (2010), ${ }^{3}$ e implica equações diferenciais autônomas, sendo necessária para evitar que, no longo prazo, o produto por trabalhador efetivo dos setores com fatores fixos seja nulo.

Quanto ao capital, este é gerado pela combinação de mínimo custo dos diferentes bens produzidos na economia, cuja produção é representada por uma função do tipo Cobb-Douglas, ou seja, com retornos constantes à escala.

\subsubsection{O comportamento das famílias}

$\mathrm{Na}$ economia do modelo teórico há um grande número de famílias idênticas e que vivem indefinidamente, podendo ser interpretadas como dinastias, e cujo número de membros cresce à taxa constante ${ }_{n}$. O agente representativo obtém um fluxo de utilidade ao consumir os bens produzidos nas diferentes regiões da economia pelos setores de arroz, outras lavouras, outros bens agropecuários, indústria e serviços, ou seja, a partir da sequência:

$$
\left\{q_{2,1}(t), q_{2,2}(t), q_{2,3}(t), q_{3,1}(t), q_{3,2}(t), q_{3,3}(t), q_{4,1}(t), q_{4,2}(t), q_{4,3}(t), q_{5}(t), q_{6}(t)\right\}_{0}^{\infty},
$$

em que $q_{2,1}(t)$ indica, por exemplo, a quantidade consumida do bem 2 (arroz) produzido na região 1 (Centro-Sul) no período $t$, ressaltando-se novamente que os setores 5 e 6 são nacionais e, portanto, não apresentam índices de região. Em particular, a ausência da cana-de-açúcar

\footnotetext{
${ }^{3}$ Ver, por exemplo, Pinto (2011), Smith \& Gemma (2014), Fang et al. (2015).
} 
entre os bens consumidos é uma característica derivada da estrutura empírica da SAM. O somatório do fluxo futuro de utilidade descontado pode ser representado por:

$\int_{0}^{\infty} \frac{u\left(q_{2,1}(t), q_{2,2}(t), \ldots, q_{4,3}(t), q_{5}(t), q_{6}(t)\right)^{1-\theta}-1}{1-\theta} e^{(n-\rho) t} d t$,

ou seja, em termos por trabalhador, é definido a partir de um índice do bem composto $q(t)$, do inverso da elasticidade de substituição intertemporal $\theta$, do parâmetro de desconto intertemporal $\rho$ e da taxa $n$.

Em cada período, o agente representativo minimiza o custo $\in$ de aquisição dos bens de consumo por trabalhador. Se a função utilidade é homotética, como no caso da especificação Cobb-Douglas aqui admitida, a função dispêndio decorrente da minimização é separável em um bem composto $q$ (Roe et al., 2010), tal que:

$\epsilon=\mathcal{E}(\boldsymbol{p}) q \equiv \min _{q_{c, i}, q_{c}}\left\{\sum_{c=2 i=1}^{4} \sum_{c, i}^{3} p_{c, i} q_{c, i}+\sum_{c=5}^{6} p_{c} q_{c}: q \leq u\left(q_{2,1}, q_{2,2}, \ldots, q_{4,3}, q_{5}, q_{6}\right)\right\}$

em que se omite os índices, enquanto $p$ indica o vetor de preços dos bens da economia. Dessa forma, $\mathcal{E}(\boldsymbol{p})$ pode ser interpretado como o preço unitário do bem de consumo composto $q$.

$\mathrm{Se} \mathcal{E}(\boldsymbol{p})$ é diferenciável nos preços, as demandas hickisianas pelos diferentes bens da economia são obtidas pelo lema de Shephard:

$\left\{\begin{array}{c}q_{c, i}=\frac{\partial \mathcal{E}(\boldsymbol{p}) q}{\partial p_{c, i}}, \quad \forall c \in\{2,3,4\}, \forall i \in I \\ q_{c}=\frac{\partial \mathcal{E}(\boldsymbol{p}) q}{\partial p_{c}}, \quad \forall c \in\{5,6\}\end{array}\right.$.

Seja o número de "trabalhadores efetivos" no momento $t$ dado por $A(0) L(0) e^{(n+x) t}, \operatorname{com} A(o)$ sendo o nível inicial da produtividade, é possível mostrar, ainda, que a restrição orçamentária associada ao problema do consumidor pode ser escrita como ${ }^{4}$ :

$\dot{\hat{k}}=\frac{1}{p_{k}}\left(\hat{w}+r_{k} \hat{k}+\sum_{s=1}^{4} \sum_{j=1}^{3} \hat{v}_{T}^{s, j} T^{s, j}+\sum_{s=1}^{3} \sum_{j=1}^{3} \hat{v}_{H}^{s, j} H^{s, j}-\hat{\jmath}\right)-(x+n+\delta) \hat{k}$

em que $\hat{k}$ é o capital por trabalhador efetivo da economia, e a notação de ponto indica variação no tempo; $\hat{w}$ e $r_{k}$ são, respectivamente, a remuneração por unidade de trabalho efetivo e a remuneração do capital; $\hat{v}_{T}^{s, j}$ e $\hat{v}_{H}^{s, j}$, por seu turno, são as remunerações-sombra, por trabalhador efetivo, da terra $\left(T^{s, j}\right)$ e da água $\left(H^{s, j}\right)$ nos setores que destes fatores se utilizam; e, finalmente, $p_{k}$ é o preço do unitário do bem de capital. Dessa forma, em cada período do tempo, a variação no estoque de capital será dada pela poupança - diferença entre renda e dispêndio -, bem como sua parcela depreciada durante o processo produtivo, e ao crescimento da força de trabalho efetiva. Além disso, quanto maior for o preço do capital, menor será sua variação em termos reais.

Finalmente, para evitar esquemas Ponzi, impõe-se a seguinte condição de transversalidade (Roe et al., 2010):

$\lim _{t \rightarrow \infty}\left[k(t) e^{-\int_{0}^{t}\left(r(v)-n-\frac{\dot{p}_{k}}{p^{k}}\right) d v}\right]=0$

ou seja, o valor presente dos ativos físicos por trabalhador em um futuro distante tende a zero.

4 O leitor pode obter em Roe et al. (2010), caps. 3 e 4, uma discussão sobre a dedução da restrição orçamentária do problema de maximização definido neste modelo multissetorial de crescimento. 


\subsubsection{Definição do preço-sombra dos recursos naturais}

No contexto de recursos naturais incorporados como fatores fixos em um modelo multissetorial de crescimento, Roe \& Smith (2015) destacaram como os conceitos de remuneração-sombra e preço-sombra são distintos entre si. Neste sentido:

[...] the unit shadow rental rate is the amount a farmer would be willing to pay for the right to purchase an additional unit of water in the current period. This is to be contrasted with a sector's unit shadow price of water, which is the amount a farmer would pay for permanent user rights to a unit of water" (Roe \& Smith, 2015, p. 9),

podendo-se fazer uma analogia com o aluguel do capital e seu preço de venda.

A valoração dos recursos naturais proposta por Roe et al. (2010) parte de uma condição de arbitragem em que, no equilíbrio, o agente deve ser indiferente entre vender uma unidade do recurso natural ao preço vigente ou mantê-la, obtendo, assim, rendimentos. Tomando como exemplo o fator terra, o valor de seu estoque no setor $s$ da região ${ }_{j}$ é dado por $p_{T}^{s, j} T^{s, j}$, então o rendimento, via taxa de juros livre de risco $r$, da venda de uma unidade deste estoque, $r p_{T}^{s, j}$, deve ser igual à remuneração $V_{T}^{s, j}$ obtida, caso se retenha esta unidade de terra, mais a variação (positiva ou negativa) do preço da terra $p_{T}^{s, j}$, de modo que:

$r p_{T}^{s, j}=V_{T}^{s, j}+\dot{p}_{T}^{s, j}$.

Tendo em conta a condição de transversalidade (7) e definindo $p_{S_{T}}^{s, j}=\frac{p_{T}^{s, j} / L}{p_{k}}$, Roe et al. (2010) solucionaram esta equação diferencial, de modo a obter o valor presente da terra no setor ${ }_{j}$. $p_{\varsigma_{T}}^{s, j}(t)=\int_{t}^{\infty} e^{-\int_{t}^{\tau}\left(r(s)-n-\frac{\dot{p}_{k}}{p_{k}}\right) d s} \frac{v_{T}^{s, j}(\tau)}{p_{k}(\tau)} d \tau, \forall s \in\{1,2,3,4\}, \forall j \in J$

Um procedimento semelhante pode ser realizado para a água, de modo a obter seu preçosombra por unidade.

\subsubsection{As firmas}

As funções de produção das firmas representativas da economia modelada podem ser classificadas em dois grupos, conforme a presença ou não de fatores fixos. Em ambos os casos, as funções de produção são do tipo Leontief, mas combinando, sob funções do tipo CobbDouglas, os fatores de produção primários. Iniciando pelos setores industrial e de serviços, ambos nacionais, estes empregam tecnologia neoclássica e linearmente homogênea nos fatores de produção capital e trabalho, e nos insumos intermediários. Nestas atividades, a tecnologia pode ser representada como:

$Y_{s}=\min \left\{F_{s}\left(A L^{s}, K^{s}\right), \frac{Y_{1,1}^{s}}{\sigma_{1,1}^{s}}, \frac{Y_{1,2}^{s}}{\sigma_{1,2}^{s}}, \ldots, \frac{Y_{4,3}^{s}}{\sigma_{4,3}^{s}}, \frac{Y_{5}^{s}}{\sigma_{s}^{s}}, \frac{Y_{6}^{s}}{\sigma_{6}^{s}}\right\}, \forall s \in\{5,6\}$.

Aqui, $Y_{I, 2}^{s}$ indica, por exemplo, a quantidade do produto 1 (cana-de-açúcar) produzido na região 2 (NordesteTO) utilizada como bem intermediário na produção do setor $s \in\{1,6\}$, enquanto $\sigma_{1,2}^{s}$ é o respectivo coeficiente insumo-produto.

No segundo grupo, das firmas que utilizam fatores fixos, inicia-se pelos setores 1 (arroz), 2 (cana-de-açúcar) e 3 (outras lavouras), em que as tecnologias, em cada região $j$, possuem como fatores de produção primários, além de trabalho e capital, os recursos naturais terra e água para irrigação, são representadas por: 
$Y_{s, j}=\min \left\{F_{s, j}\left(A L^{s, j}, K^{s, j}, \mathcal{B} T^{s, j}, \Lambda H^{s, j}\right), \frac{Y_{1,1}^{s, j}}{\sigma_{l, 1}^{s, j}}, \frac{Y_{1,2}^{s, j}}{\sigma_{l, 2}^{s, j}}, \ldots, \frac{Y_{4,3}^{s, j}}{\sigma_{4,3}^{s, j}}, \frac{Y_{5}^{s, j}}{\sigma_{5}^{s, j}}, \frac{Y_{6}^{s, j}}{\sigma_{6}^{s, j}}\right\}, \forall s \in\{1,2,3\}, \forall j \in J$,

em que, por exemplo, $Y_{4,3}^{s, j}$ indica a demanda do setor $s$ na região $j$ pelo produto 4 (outros produtos agropecuários) da região 3 (NorteExTO). A presença de fatores fixos - no caso, terra e água para irrigação - permite construir o problema da firma em termos da maximização de lucro e correspondente função valor adicionado

Por seu turno, o setor produtor dos demais bens agropecuários, indexado pelo número 4 , engloba atividades do setor agropecuário que não aquelas de lavouras - e que, portanto, não utilizam suplementação hídrica -, tais como a pecuária e a produção florestal, e diferencia-se por considerar como fator fixo apenas a terra, de modo que sua função de produção seja:

$Y_{4, j}=\min \left\{F_{4, j}\left(A L^{4, j}, K^{4, j}, \mathcal{B} T^{4, j}\right), \frac{Y_{1,1}^{4, j}}{\sigma_{1,1}^{4, j}}, \frac{Y_{1,2}^{4, j}}{\sigma_{1,2}^{4, j}}, \ldots, \frac{Y_{4,3}^{4, j}}{\sigma_{4,3}^{4, j}}, \frac{Y_{5}^{4, j}}{\sigma_{5}^{4, j}}, \frac{Y_{6}^{4, j}}{\sigma_{6}^{4, j}}\right\}, \forall j \in J$

\subsubsection{O equilíbrio intratemporal}

Dada a sequência $\{\hat{k}(t), \hat{\epsilon}(t)\}_{0}^{\infty}$, o equilíbrio competitivo da economia pode ser caracterizado pela sequência

$\left\{\hat{w}(t), r^{k}(t), \hat{y}_{5}(t), \hat{y}_{6}(t), p_{1,1}(t), p_{1,2}(t), p_{1,3}(t), p_{6}(t)\right\}_{0}^{\infty}$

que satisfaz as seguintes condições:

i) Lucro zero nos setores industrial ( 5 ) e de serviços ( 6 )

ii) Equilíbrio do mercado de trabalho

iii) Equilíbrio do mercado de capital

iv) Equilíbrio dos mercados regionais de cana-de-açúcar

v) Equilíbrio do mercado de serviços

A primeira condição impõe que a margem bruta do setor, ou seja, o preço de venda menos o consumo intermediário, seja igual ao custo econômico da produção. Roe et al. (2010) denominaram esta margem de "preço de valor adicionado" (value added price). A segunda e a terceira condições valem-se da aplicação dos lemas de Shephard e Hotelling para obter as demandas pelos fatores de produção, enquanto a quarta condição explicita o fato de a produção de cana-de-açúcar de cada região destinar-se apenas ao consumo intermediário dos setores locais e dos setores nacionais (indústria e serviços). A quinta condição vincula o dispêndio total ao mercado de serviços, determinando que o consumo real do bem de serviços é a diferença entre a oferta total, o consumo intermediário e a parte investida desta produção.

A partir das expressões da condição (i), soluciona-se para $\hat{w}$ e $r^{k}$, de modo a obter formas reduzidas que definem salário e remuneração do capital em função dos preços domésticos, tais que:

$$
\begin{aligned}
& \tilde{w}\left(p_{1,1}, p_{1,2}, p_{1,3}, p_{6}\right), \\
& \tilde{r}\left(p_{1,1}, p_{1,2}, p_{1,3}, p_{6}\right) .
\end{aligned}
$$

Estas formas reduzidas podem ser substituídas nas funções oferta dos setores industrial e de serviços, bem como na restrição orçamentária (6). As demais condições de equilíbrio intertemporal, em conjunto com a restrição orçamentária (6), e as formas reduzidas em (13), permitem obter a equação diferencial que descreve a evolução do estoque de capital por 
trabalhador efetivo a partir de seu próprio nível e do comportamento dos preços endógenos, de modo que:

$$
\dot{\hat{k}}=\tilde{K}\left(p_{1,1}, p_{1,2}, p_{1,3}, p_{6}, \hat{k}\right)
$$

\subsubsection{O equilíbrio intertemporal}

Assim como em Roe et al. (2010), vigentes as condições de não arbitragem na economia, o retorno sobre o valor total dos ativos por trabalhador possuídos pelas famílias, $a(t)$, deve ser a taxa de juros livre de risco $r(t)$. Convém ressaltar que o único preço que efetivamente influencia o consumo das famílias é o preço do bem de serviços, uma vez que o setor de canade-açúcar produz bens apenas para consumo intermediário e que os bens transacionáveis são negociados a preços exógenos. Portanto, o hamiltoniano correspondente à maximização de (3) pode ser escrito como:

$J=\frac{q(t)^{I-\theta}-1}{1-\theta} e^{(n-\rho) t}+\xi(t)\left[w(t)+(r(t)-n) a(t)-\mathcal{E}\left(p_{6}\right) q\right]$

em que $\xi(t)$ é uma variável de coestado ou adjunta.

Admitindo a elasticidade intertemporal unitária, tal que $\theta=1$, e seguindo Barro \& Sala-iMartin (2004), pode-se mostrar que a equação de Euler associada ao problema é dada por:

$\frac{\dot{\hat{\epsilon}}}{\hat{\epsilon}}=\frac{r_{k}}{p_{k}}-x-\delta-\rho+\psi_{6} \frac{\dot{p}_{6}}{p_{6}}$

em que $\psi_{6}$ corresponde à elasticidade associada ao bem de serviços na função utilidade do tipo Cobb-Douglas. Esta é a primeira equação diferencial de um sistema cuja segunda trata-se da própria restrição orçamentária (6), com as devidas substituições dos argumentos por suas formas reduzidas, conforme realizado em (14), enquanto a terceira tem origem na condição intratemporal (iv). Neste último caso, reconhecendo que o excesso de oferta $\hat{\chi}_{1, j}$ no mercado de cana-de-açúcar em cada região deve ser nulo em todo o horizonte temporal, então:

$\dot{\hat{\chi}}_{1, j} \equiv \frac{d \hat{\chi}_{j}\left(p_{3, l}, p_{3,2}, p_{3,3}, p_{6}, \hat{k}\right)}{d t}=0, \forall j \in J$,

ou seja, a variação do excesso de oferta de cana-de-açúcar (por trabalhador efetivo) ${ }^{\hat{\chi}_{1, j}}$, que depende das variáveis endógenas do modelo, deve ser nulo em cada região ${ }^{j}$.

Dessa forma, tem-se um sistema com equações diferenciais dadas em (14), (16) e (17), e que pode ser numericamente solucionado para as trajetórias das variáveis de interesse. Dada a característica autônoma do sistema de equações diferenciais, pode-se aplicar o método timeelimination, proposto por Mulligan \& Sala-i-Martin (1991).

\subsection{Calibração e solução numérica}

O modelo desenvolvido pode ser quase imediatamente ajustado aos dados de uma SAM, porém alguns parâmetros devem ser estabelecidos exogenamente por meio de um exercício de decomposição do crescimento. Ressalta-se que as taxas de crescimento exógenas incorporadas à solução numérica do modelo, como aquelas da produtividade e da força de trabalho, referem-se 
a tendências determinísticas exponenciais ajustadas às séries temporais dos dados, buscando refletir o padrão de longo prazo da economia, em acordo com a natureza do modelo utilizado.

No presente trabalho, em acordo com o modelo anteriormente descrito, a SAM apresenta seis setores, três regiões e quatro fatores de produção, mas não engloba, por exemplo, o governo como um agente em separado. Sua construção deu-se a partir de uma base de dados desenvolvida para a aplicação em modelos computáveis de equilíbrio geral como aqueles derivados do ORANI-G (Horridge, 2003).

Para desagregar da renda da terra a parcela atribuível à água utilizada nos sistemas de suplementação hídrica das lavouras, optou-se por aplicar a estratégia de Haqiqi et al. (2016), obtendo-se de maneira residual a contribuição da água de irrigação para a renda das lavouras. A ausência de informações suficientemente desagregadas no Censo Agropecuário mostrouse impeditiva para a estimação econométrica da função de produção, como a realizada por Smith \& Gemma (2014). Cabe notar, contudo, que Haqiqi et al. (2016) utilizaram os termos "irrigado" (irrigated) e "sequeiro" (rainfed), o que seria restritivo para o caso brasileiro e, além disso, valeram-se da participação dos setores na produção física, enquanto aqui se optou por utilizar o valor da produção, uma vez que as medidas de produção física disponibilizadas no Censo Agropecuário são diferentes entre produtos, o que é inconveniente para o nível de agregação considerado. Não obstante estas diferenças, o procedimento é compatível com a hipótese de que os produtos sejam homogêneos e, portanto, vendidos aos mesmos preços.

Dividiu-se, então, cada uma das três lavouras nos regimes com e sem suplementação hídrica, conforme a participação de cada método no valor da produção, de acordo com o Censo Agropecuário de 2006. Uma vez que a SAM possuía como referência o ano de 2005, a área considerada foi aquela da Pesquisa Agrícola Municipal (PAM) do Instituto Brasileiro de Geografia e Estatística (2019) também referente a 2005, em que se admitiu que a participação da área com suplementação hídrica fosse a mesma observada no Censo Agropecuário de 2006. Cabe notar que a adoção desta estratégia residual, dependente da identificação de setores com e sem uso de suplementação hídrica, explica a não consideração do uso da água nos setores industrial e da pecuária, uma vez que, em ambos, não é possível construir dois grupos cujas tecnologias difiram unicamente pela utilização da água.

Para a decomposição do crescimento da economia brasileira, e obtenção dos parâmetros do modelo empírico a ela relacionados, adotou-se como referência o período entre 1981 e 2013, sendo os dados originários da base Ipeadata do Instituto de Pesquisa Econômica Aplicada (2019) e World Development Indicators (Banco Mundial, 2019), além de diversas edições da PNAD. Considerou-se a seguinte função de produção para a economia brasileira:

$$
Y=(A L)^{\alpha} K^{1-\alpha},
$$

em que $Y$ é o produto da economia, $A$ o nível da produtividade aumentadora de trabalho, $L$ é a força de trabalho, $K$ é o estoque de capital e $\alpha$ é a participação do fator trabalho na renda.

O estoque de capital foi calculado junto com a taxa de depreciação conforme metodologia de Conesa, Kehoe \& Ruhl (2007), utilizando dados de formação bruta de capital fixo (FBKF), além da relação entre consumo de capital fixo e PIB (Banco Mundial, 2019). Os resultados indicaram que o estoque de capital em 2005 era de $\mathrm{R} \$ 5,8$ trilhões, a preços do referido ano, e a taxa de depreciação de $4,07 \%$ a.a. O procedimento empregado implicou uma razão capital-produto de 2,71 que, ao passar pela suavização proposta no início desta seção, se reduz para 2,70.

A evolução da força de trabalho foi obtida a partir das edições entre 1981 e 2013 da PNAD, e submetidos à compatibilização proposta por Barbosa Filho \& Pessôa (2014). Dessa forma, o 
pessoal ocupado corresponde aos indivíduos que exerceram trabalho remunerado, ou trabalho não remunerado por 15 horas ou mais na semana de referência da pesquisa. O procedimento de ajuste de tendência determinística aplicado à série obtida de pessoal ocupado resultou em uma taxa de crescimento de $2,15 \%$.

A série obtida para o estoque de capital, conjuntamente à da evolução da força de trabalho e a participação do capital na renda - no caso de um único setor - obtida diretamente da SAM, permitiu, então, o cálculo por resíduo da taxa de crescimento da produtividade Harrodneutra. A soma da taxa de crescimento da produtividade e da força de trabalho implicam que, dada a condição de sustentabilidade imposta (conforme a expressão 1), a produtividade dos fatores fixos cresça à taxa de 2,75\% a.a. Este valor, bastante superior ao crescimento da produtividade agregada, é compatível com as características da economia brasileira, em que a agropecuária se destaca por seu dinamismo frente aos outros grandes setores, e está em acordo com estimativas realizadas para o setor por diferentes metodologias (Bragagnolo et al., 2010; Gasques et al., 2012; Santos \& Spolador, 2018).

Dada a estrutura do modelo proposto, o valor numérico das dotações dos recursos naturais (fatores fixos) é relevante apenas para a análise de valores-sombra unitários. Do contrário, se o objetivo for unicamente estimar o valor total do estoque dos fatores fixos em determinado setor, poder-se-ia simplesmente definir todos eles como unitários.

Para o fator terra nos setores de lavouras (cana-de-açúcar, arroz e outras lavouras), consideraram-se os dados sobre de área colhida PAM de 2005 (Instituto Brasileiro de Geografia e Estatística, 2019). No caso das outras atividades agropecuárias, espera-se que a maior parte da área utilizada corresponda à produção pecuária e, em menor grau, à produção florestal. Como não existem levantamentos sistemáticos destas áreas, optou-se por obter apenas a estimativa do valor do estoque total do fator.

Como mencionado, as informações sobre o volume de água utilizado referentes ao ano de 2006 são provenientes da base de dados elaborada pela FUNARBE (Fundação de Apoio à Universidade Federal de Viçosa, 2011), e correspondem ao conceito de "volume retirado", embora o termo não fosse preciso no caso da cana-de-açúcar, uma vez que acabava incorporando a aplicação de resíduos agroindustriais. A Tabela 1 sumariza os valores dos fatores fixos terra e água considerados no modelo.

Tabela 1. Quantidade dos fatores fixos considerados no modelo.

\begin{tabular}{lccc} 
& Cana-de-açúcar & Arroz em casca & Outras lavouras \\
Área colhida por lavoura e região do modelo (ha) & & \\
Centro-Sul & 4.660 .039 & 2.455 .528 & 40.378 .307 \\
NordesteTO & 1.130 .574 & 1.003 .562 & 10.722 .218 \\
NorteExTO & 14.905 & 456.765 & 1.824 .438 \\
Água destinada à irrigação por lavoura e região do modelo $\left(1.000 .000 \mathrm{~m}^{3}\right)$ & \\
Centro-Sul & $6.214,17$ & $7.371,03$ & $2.468,17$ \\
NordesteTO & $8.572,77$ & 439,20 & $2.521,72$ \\
NorteExTO & 3,61 & 43,97 & 107,34 \\
\hline
\end{tabular}

Fonte: Elaboração própria a partir de FUNARBE (Fundação de Apoio à Universidade Federal de Viçosa, 2011) e IBGE (Instituto Brasileiro de Geografia e Estatística, 2019).

Neste ponto, para a calibração do modelo empírico restam os parâmetros relativos às preferências intertemporais. O primeiro deles, o inverso da elasticidade de substituição, $\theta$, já foi definido durante a apresentação do modelo como unitário e, assim como a hipótese de sustentabilidade, esta suposição está presente em diversos trabalhos derivados do modelo 
original de Roe et al. (2010), tendo como vantagem tornar a função utilidade logarítmica, com benefícios em termos de procedimentos computacionais.

O parâmetro de desconto intertemporal $\rho$ associa-se à taxa de poupança e foi obtido a partir do ajuste de uma tendência determinística à série da taxa de investimento da economia brasileira, disponibilizada pelo IPEA (Instituto de Pesquisa Econômica Aplicada, 2019), bem como à relação capital-produto, ambas com os valores correspondentes ao ano de 2005, tal qual realizado para os parâmetros do crescimento da produtividade Harrod-neutra $(x)$ e da força de trabalho $(n)$. Em seguida, fornecidos os demais parâmetros do modelo, o valor de $\rho$ foi escolhido de modo que a taxa de investimento resultante da simulação fosse semelhante ao seu valor tendencial identificado no procedimento de suavização da série. Assim, a taxa de investimento, referência para a obtenção do parâmetro de desconto intertemporal, foi de 17,58\%, enquanto o valor de $\rho$ foi fixado em 0,1084 .

A solução numérica para o sistema de equações diferenciais, descrito na subseção 3.1.6, foi obtida numericamente com o modelo calibrado no software Mathematica, versão 11.2, em sua linguagem de alto nível Wolfram Language. Excetuando-se as dotações dos fatores fixos, já apresentados na Tabela 1, os parâmetros externos à SAM são sumarizados na Tabela 2.

Tabela 2. Parâmetros do modelo externos à Matriz de Contabilidade Social.

\begin{tabular}{llc}
\multicolumn{1}{c}{ Taxa de depreciação } & $\delta$ & $\mathbf{0 . 0 4 0 7}$ \\
Inverso da elasticidade de substituição intertemporal & $\theta$ & 1 \\
Taxa de preferência temporal & $\rho$ & 0,1084 \\
Taxa Harrod & $x$ & 0,0059 \\
Taxa de crescimento da força de trabalho & $n$ & 0,0215 \\
Taxa de crescimento da produtividade dos fatores fixos & $\eta$ & 0,0275 \\
Relação capital-produto em 2005 & $K(0) / Y(0)$ & 2,7025 \\
\hline
\end{tabular}

Fonte: Elaboração própria a partir de Instituto de Pesquisa Econômica Aplicada (2019) e Banco Mundial (2019).

\section{Resultados e discussão}

\subsection{O crescimento setorial}

A Figura 2 mostra a evolução projetada da taxa de crescimento instantânea dos diferentes setores da economia, a partir da solução numérica do modelo multissetorial de crescimento. A existência de taxas de crescimento semelhantes nas produções de arroz, de outros produtos da lavoura e de outros produtos da agropecuária decorre da presença, na base de dados, de tecnologias semelhantes, excetuando-se a intensidade no uso da terra e da água.

Nota-se que as atividades possuem dinâmicas distintas de crescimento, sendo notável o maior crescimento inicial das atividades agropecuárias, exceto da cana-de-açúcar. O padrão encontra-se de acordo com características da economia brasileira com maior dinamismo do setor agropecuário. No caso da cana-de-açúcar, esta é afetada pelo comportamento da indústria, que cresce menos ao longo da transição, com efeito menor na região denominada NorteExTO. 

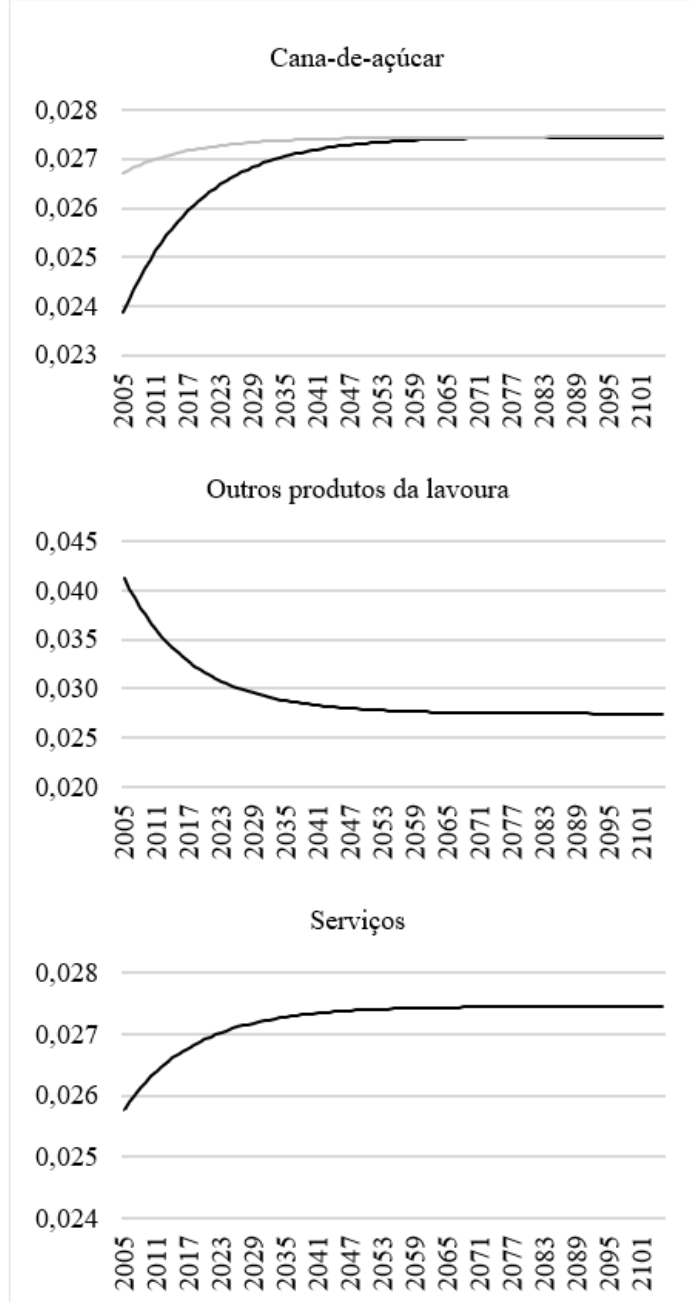
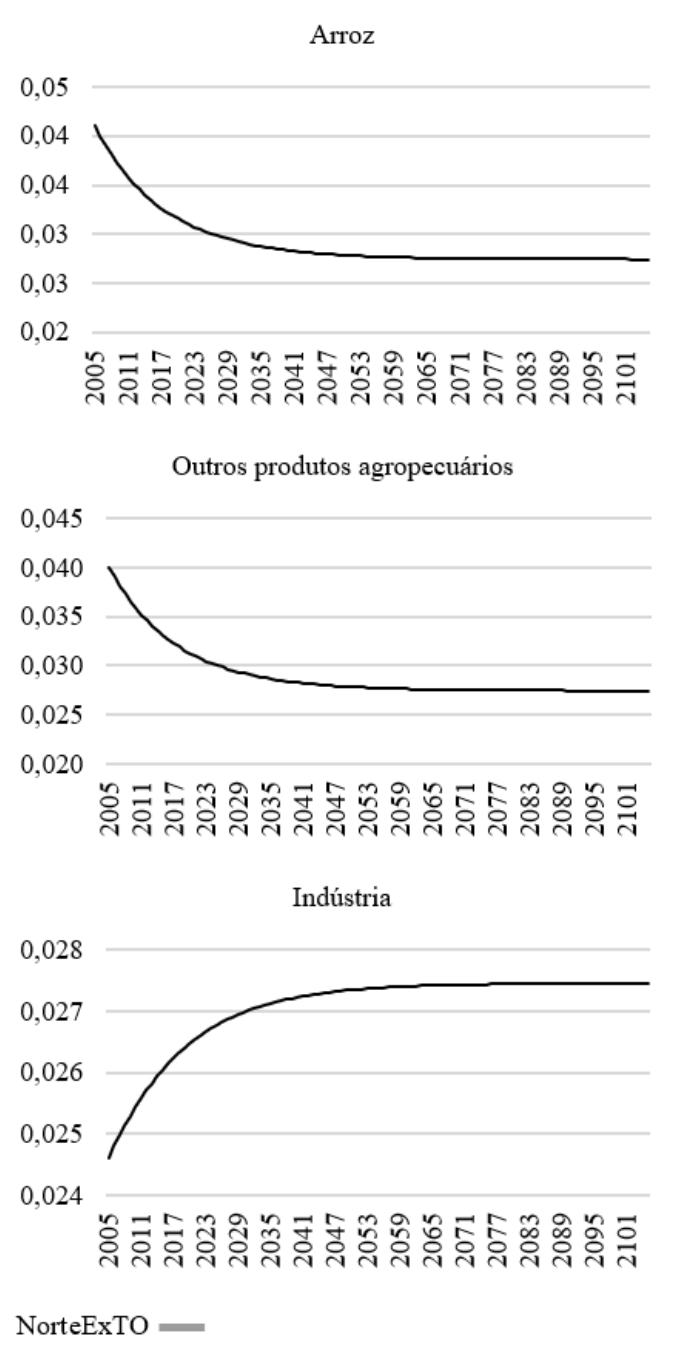

Figura 2. Evolução projetada das taxas de crescimento do produto setorial. Nota: Excetuando o setor de cana-de-açúcar na região NorteExTO, todos os setores possuem trajetórias das taxas de crescimento sobrepostas entre regiões. Por simplicidade de exibição, optou-se por destacar nos gráficos apenas valores relativos à região Centro-Sul, bem como a produção de cana-de-açúcar na região NorteExTO. Fonte: Resultados do modelo.

Na projeção para a indústria, este setor cresce a uma taxa inferior àquela do setor de serviços, demonstrando um processo de mudança estrutural. Este comportamento dá-se em decorrência de diferentes intensidades de capital e, em sendo o setor de serviços mais intensivo em trabalho, o crescimento elevado da força de trabalho o beneficia relativamente à indústria, que é mais intensiva em capital.

\subsection{Remuneração-sombra (shadow-rent) da água}

Os resultados referentes à remuneração-sombra (shadow-rent) da água nos três setores de lavouras são apresentados na Tabela 3. Estes valores devem ser compreendidos como o montante que os produtores estariam dispostos a pagar por uma unidade do recurso natural ao longo de um período, ou seja, no presente caso, o valor em reais por metro cúbico utilizado 
em determinado ano. Dessa forma, os valores equivaleriam conceitualmente à razão entre o valor adicionado pela água em cada um dos setores e regiões - conforme seria observado na SAM - e a quantidade de água utilizada em cada um deles.

Tabela 3. Evolução projetada das remunerações-sombra da água por setor e região.

\begin{tabular}{|c|c|c|c|c|c|c|c|c|c|}
\hline \multirow[b]{2}{*}{ Ano } & \multicolumn{3}{|c|}{ Cana-de-açúcar } & \multicolumn{3}{|c|}{ Arroz } & \multicolumn{3}{|c|}{ Outras lavouras } \\
\hline & $\begin{array}{l}\text { Centro- } \\
\text { Sul }\end{array}$ & NordesteTO & $\begin{array}{l}\text { Norte } \\
\text { ExTO }\end{array}$ & $\begin{array}{l}\text { Centro- } \\
\text { Sul }\end{array}$ & NordesteTO & $\begin{array}{l}\text { Norte } \\
\text { ExTO }\end{array}$ & $\begin{array}{l}\text { Centro- } \\
\text { Sul }\end{array}$ & NordesteTO & $\begin{array}{l}\text { Norte } \\
\text { ExTO }\end{array}$ \\
\hline 2005 & 0,001 & 0,001 & 0,090 & 0,007 & 0,002 & 0,021 & 0,041 & 0,030 & 0,010 \\
\hline 2015 & 0,001 & 0,001 & 0,118 & 0,011 & 0,003 & 0,030 & 0,059 & 0,044 & 0,014 \\
\hline 2025 & 0,001 & 0,002 & 0,154 & 0,014 & 0,004 & 0,042 & 0,081 & 0,060 & 0,020 \\
\hline 2035 & 0,002 & 0,002 & 0,203 & 0,019 & 0,006 & 0,056 & 0,108 & 0,080 & 0,026 \\
\hline 2045 & 0,002 & 0,003 & 0,267 & 0,026 & 0,008 & 0,074 & 0,144 & 0,107 & 0,035 \\
\hline 2055 & 0,003 & 0,003 & 0,351 & 0,034 & 0,010 & 0,098 & 0,190 & 0,141 & 0,046 \\
\hline 2065 & 0,004 & 0,004 & 0,462 & 0,045 & 0,013 & 0,129 & 0,251 & 0,186 & 0,061 \\
\hline 2075 & 0,005 & 0,006 & 0,608 & 0,059 & 0,018 & 0,170 & 0,330 & 0,245 & 0,080 \\
\hline 2085 & 0,006 & 0,008 & 0,800 & 0,078 & 0,023 & 0,224 & 0,435 & 0,323 & 0,106 \\
\hline 2095 & 0,008 & 0,010 & 1,052 & 0,103 & 0,030 & 0,295 & 0,572 & 0,425 & 0,139 \\
\hline 2105 & 0,011 & 0,013 & 1,385 & 0,135 & 0,040 & 0,388 & 0,753 & 0,559 & 0,183 \\
\hline
\end{tabular}

Fonte: Resultados do modelo.

Apesar de os estados da região NorteExTO possuírem parcelas minoritárias das produções de arroz e cana-de-açúcar, esta região apresenta valores da remuneração-sombra da água superiores às demais. Uma conjectura sobre os valores simulados é de que a presença de irrigação esteja, na realidade, servindo de proxy para outras melhorias tecnológicas presentes nas áreas com este regime de produção, refletidas em uma maior produtividade e, assim, maior remuneração. Esta característica teria sido, então, incorporada ao modelo através de uma maior remuneração da água na SAM, resultando em valores por metro cúbico da ordem de $R \$ 0,090, R \$ 0,021$ e $R \$ 0,010$ nas produções de cana-de-açúcar, arroz e outras lavouras, respectivamente.

Por seu turno, nas regiões Centro-Sul e NordesteTO, os valores mais elevados da remuneração da água são encontrados na produção de outras lavouras, isto é, 0,041 e 0,030 por metro cúbico, respectivamente. Este resultado parece estar em acordo com o processo de adoção de sistemas irrigados na fronteira agrícola brasileira, concentrada na região Centro-Oeste, e com os diferenciais produtivos na região NordesteTO. Como apontado por ANA (Agência Nacional de Águas, 2017), a expansão recente da agricultura brasileira tem ocorrido em regiões de clima desfavorável em parte ou durante todo o ano, o que incentiva a adoção de regimes irrigados que, ao mesmo tempo, tendem a promover ganhos significativos de produtividade.

No caso da cana-de-açúcar, esta atividade apresenta as menores remunerações pela água nas regiões Centro-Sul e NordesteTO, embora seja a maior consumidora de água. Pode-se afirmar que esta remuneração-sombra reflete a baixa produtividade da água no setor que, por sua vez, pode ter origem em aspectos agronômicos e institucionais. Na produção de canade-açúcar, reconhece-se que a necessidade de suplementação hídrica ocorre geralmente nas fases iniciais de desenvolvimento da planta, pois, a partir de certo estágio, torna-se desejável a ocorrência de menor disponibilidade de água, o que leva a uma maior concentração de açúcares (Aude, 1993). Assim, em um cenário de poucas chuvas, busca-se apenas equalizar, por meio da suplementação hídrica o desenvolvimento inicial da planta vis-à-vis um regime pluviométrico adequado, com poucos efeitos sobre o resultado final da produção. 
Simultaneamente, durante a produção de etanol - que possui maior participação no mix de produção das usinas da região Centro-Sul - gera-se vinhaça, um resíduo com potencial poluente e que, por força da legislação ambiental, não pode ser despejado em corpos hídricos. Dessa forma, o setor busca lançar o resíduo na lavoura como forma de suplementação hídrica das fases iniciais de crescimento da planta, fornecendo também outros nutrientes. Por outro lado, dada a existência de diversas restrições quanto à dose de vinhaça aplicada por hectare (Companhia Ambiental do Estado de São Paulo, 2015), existe incentivo à expansão da área equipada para irrigação/fertirrigação, o que pode levar ao fornecimento adicional de água mesmo em parcelas da lavoura em que o mesmo não seria estritamente necessário. Resguardando-se a expectativa de que o recurso não seja aplicado a ponto de prejudicar as lavouras, a utilização da água ocorrerá até que seu produto marginal seja nulo, contribuindo para que, no agregado deste setor, a remuneração do fator de produção seja bastante baixa, especialmente no Centro-Sul.

No caso do Nordeste brasileiro, a produção de cana-de-açúcar concentra-se no litoral em que vigoram maiores índices pluviométricos (Serviço Geológico do Brasil, 2019; União da Indústria de Cana-de-Açúcar, 2019), o que reduziria a necessidade de irrigação, mesmo nas fases iniciais. Além disso, as usinas da região possuem menor participação do etanol no mix de produção, gerando menos resíduos a serem lançados ao solo, o que pode levar a uma maior seletividade das áreas a serem fertirrigadas vis-à-vis a região Centro-Sul, e refletir-se em uma maior produtividade marginal da água, logo com maior remuneração-sombra, embora, em termos intersetoriais, ela continue a ser considerada baixa.

Ao longo do tempo, com montantes fixos de água disponível, o crescimento das remunerações em todos os setores reflete o aumento da demanda resultante do processo de desenvolvimento econômico. Dessa forma, à medida que os setores irrigados crescem, ainda que a taxas distintas, o aumento dos preços-sombra seria a forma de manter o equilíbrio entre oferta e demanda pelo recurso natural. Entre as atividades, a produção de arroz apresenta o maior crescimento da remuneração-sombra da água, seguida por outras lavouras e, bastante abaixo, cana-deaçúcar. Em particular, esta última, além de ser o setor com menores valores unitários, como já mencionado, é a menos beneficiada ao longo da dinâmica da transição (ilustrada na Figura 2), o que se reflete em um menor crescimento da remuneração da água.

Tendo em conta a distinção entre remuneração-sombra e preço-sombra realizada por Roe \& Smith (2015), caso se comparem os valores obtidos no modelo com os vigentes em sistema de cobrança implementados no Brasil, mostra-se mais adequado utilizar valores de remuneraçãosombra e não os preços-sombra, na medida em que a cobrança no país é realizada por metro cúbico utilizado - tanto no conceito de retirada quanto no de consumo - e não em um esquema de cotas que garantiriam, de maneira permanente, o acesso dos produtores a um montante fixo do recurso. Gelain (2018) apresentou, a partir da página eletrônica da Agência Nacional de Águas, um levantamento de tarifas cobradas no Brasil pela retirada da água, sendo estes valores utilizados para referência; assim, conforme a referida autora, políticas de cobrança pelo uso da água ocorrem apenas em 16 estados brasileiros, sendo apenas um na região Norte, o Tocantins, o que reforça suas peculiaridades e a opção do presente trabalho em incorporá-lo à região NordesteTO do modelo.

No Centro-Sul, a produção de arroz encontra-se fortemente concentrada no Rio Grande do Sul, estado que não possuía uma regulamentação de cobrança pelo uso da água. Caso fosse considerado o valor médio da cobrança na região Centro-Sul, conforme apresentado por Gelain (2018), mesmo excluindo os valores mais elevados de São de Paulo e Paraná, é razoável interpretar que o valor proposto em 2005 encontrar-se-ia acima da remuneraçãosombra, embora para 2015 tal afirmação seja menos assertiva. Na produção do NordesteTO, 
para a cultura do arroz, o valor médio cobrado pelo uso da água já se encontraria acima da remuneração-sombra.

No caso da cana-de-açúcar, o valor a ser cobrado encontrar-se-ia acima da remuneraçãosombra tanto no Centro-Sul quanto no NordesteTO, devido à baixa produtividade de água nestas atividades. Todavia, na atividade canavieira, parte significativa da água fornecida às lavouras tem origem em resíduos agroindustriais, os quais não incidiriam nenhuma cobrança e, nos anos de 2005 e 2006, utilizados para calibração do modelo, as políticas de cobrança mostravam-se ainda incipientes, ou seja, a tarifa era efetivamente zero naquele momento.

Por outro lado, no grupo de outras lavouras, os elevados ganhos de produtividade resultantes do uso de irrigação não estariam sendo adequadamente refletidos nos valores de cobrança, ao menos nas regiões Centro-Sul e NordesteTO. Isso constitui um incentivo à utilização da irrigação nestas áreas, havendo espaço para crescimento da técnica, não obstante seja necessário atentar para a própria capacidade de provimentos das bacias hidrográficas.

De maneira geral, os resultados evidenciam que o valor econômico da água é baixo, em linha com muitos trabalhos disponíveis na literatura internacional, especialmente com metodologia semelhante (Roe \& Smith, 2015; Smith et al., 2015; Tsur et al., 2004), embora possam diferir de outros estudos realizados para o caso brasileiro no que se refere à magnitude dos valores. Os resultados obtidos encontrar-se-iam próximos aos limites inferiores observados por Frizzone et al. (1997) e Torres et al. (2012), e divergindo de demais trabalhos, como os de Teixeira (1990), Pinheiro \& Shirota (2000) e Kelman \& Ramos (2005)5. Cabe notar que os trabalhos existentes para o Brasil apresentam foco em experiências de pequena escala, especialmente na região Nordeste, o que pode justificar a presença de valores tipicamente mais elevados, resultantes de um uso intensivo da irrigação em áreas pequenas. No caso de Torres et al. (2012), o estudo circunscreveu um conjunto de cidades na bacia do Rio São Francisco, dando um caráter mais agregado à análise, e gerou estimativas de que, na maior parte do ano, o valor econômico do metro cúbico de água era nulo, embora pudesse alcançar dezenas de reais em situações de extrema restrição hídrica. Dessa forma, a abrangência espacial do trabalho, o momento do ano ao qual os dados se referem, e seu caráter micro ou macroeconômico, parecem relevantes para os valores calculados.

Enquanto a remuneração-sombra da água apresenta forte relação com as políticas de cobrança por seu uso, o preço-sombra e, consequentemente, o valor do estoque deste recurso natural associam-se à riqueza econômica, tal qual a estimação do capital físico de uma economia. Obviamente, aqui, a riqueza associada à água tem caráter unicamente econômico, excluindose conceitos de valor de não uso.

Como já destacado, o preço-sombra de um recurso natural seria o valor a ser pago para garantir a acesso permanente a ele, seja a propriedade de um hectare de terra, ou a utilização de um metro cúbico de água em cada ano por tempo indefinido. Dadas as considerações acerca da remuneração-sombra da água na subseção 3.1.3 e, conforme evidenciado pela expressão (8), a dinâmica dos preços-sombra de cada um dos fatores fixos deve refletir em alguma medida a evolução desta remuneração. A Tabela 4 mostra, portanto, a evolução dos preços-sombra do metro cúbico da água nos três setores de lavouras em cada uma das regiões consideradas, ou seja, o valor que os produtores deveriam pagar para garantir o direito permanente de utilizar um metro cúbico de água a cada ano.

\footnotetext{
5 Embora se refiram a áreas geográficas específicas e métodos de estimação diferentes deste trabalho, apenas a título de comparação, menciona-se que Pinheiro \& Shirota (2000) obtiveram $R \$$ 0,141 (preço eficiente), Teixeira (1990) obteve valores entre $R \$ 15,74$ e 36,85 a preços de dezembro de 2018, e Kelman \& Ramos (2005) obtiveram estimativas de $\mathrm{R} \$ 0,04$ e $R \$ 1,62$.
} 
Tabela 4. Evolução projetada dos preços-sombra da água por setor e região.

\begin{tabular}{|c|c|c|c|c|c|c|c|c|c|}
\hline \multirow[b]{2}{*}{ Ano } & \multicolumn{3}{|c|}{ Cana-de-açúcar } & \multicolumn{3}{|c|}{ Arroz } & \multicolumn{3}{|c|}{ Outras lavouras } \\
\hline & $\begin{array}{l}\text { Centro- } \\
\text { Sul }\end{array}$ & $\begin{array}{c}\text { Nordeste } \\
\text { TO }\end{array}$ & $\begin{array}{l}\text { Norte } \\
\text { ExTO }\end{array}$ & $\begin{array}{l}\text { Centro- } \\
\text { Sul }\end{array}$ & $\begin{array}{c}\text { Nordeste } \\
\text { TO }\end{array}$ & $\begin{array}{l}\text { Norte } \\
\text { ExTO }\end{array}$ & $\begin{array}{l}\text { Centro- } \\
\text { Sul }\end{array}$ & $\begin{array}{c}\text { Nordeste } \\
\text { TO }\end{array}$ & $\begin{array}{c}\text { Norte } \\
\text { ExTO }\end{array}$ \\
\hline 2005 & 0,008 & 0,010 & 1,047 & 0,093 & 0,028 & 0,267 & 0,518 & 0,384 & 0,126 \\
\hline 2015 & 0,011 & 0,013 & 1,361 & 0,127 & 0,038 & 0,365 & 0,708 & 0,525 & 0,172 \\
\hline 2025 & 0,014 & 0,017 & 1,782 & 0,170 & 0,050 & 0,489 & 0,948 & 0,704 & 0,231 \\
\hline 2035 & 0,018 & 0,023 & 2,338 & 0,226 & 0,067 & 0,649 & 1,259 & 0,934 & 0,306 \\
\hline 2045 & 0,024 & 0,030 & 3,074 & 0,298 & 0,088 & 0,858 & 1,663 & 1,234 & 0,405 \\
\hline 2055 & 0,031 & 0,039 & 4,042 & 0,393 & 0,116 & 1,131 & 2,193 & 1,628 & 0,534 \\
\hline 2065 & 0,041 & 0,052 & 5,318 & 0,518 & 0,153 & 1,490 & 2,888 & 2,144 & 0,703 \\
\hline 2075 & 0,054 & 0,068 & 6,998 & 0,682 & 0,202 & 1,961 & 3,802 & 2,822 & 0,926 \\
\hline 2085 & 0,071 & 0,090 & 9,208 & 0,898 & 0,266 & 2,581 & 5,004 & 3,715 & 1,218 \\
\hline 2095 & 0,093 & 0,118 & 12,117 & 1,182 & 0,350 & 3,397 & 6,586 & 4,889 & 1,604 \\
\hline 2105 & 0,122 & 0,155 & 15,946 & 1,555 & 0,460 & 4,471 & 8,668 & 6,434 & 2,110 \\
\hline
\end{tabular}

Fonte: Resultados do modelo.

Como seria esperado, o preço-sombra da água nos três setores é bastante superior à remuneração-sombra: em 2005, a relação rendimento/preço da água variou entre 7,1\% na produção de arroz da região Nordeste TO e 12,5\% na produção de cana-de-açúcar do CentroSul. Estes valores relacionam-se à dinâmica de crescimento dos setores, de modo que a canade-açúcar, ao apresentar menores taxas de crescimento, tem maior desconto intertemporal, resultando em uma maior relação remuneração/preço comparativamente às produções de arroz e de outras lavouras. Embora as taxas de crescimento destes preços-sombra sejam convergentes para aquela de longo prazo, o recurso destinado à produção canavieira possui menor variação, refletindo também na redução de seu preço na trajetória de longo prazo da economia.

Em termos absolutos, em 2005, o maior preço-sombra é observado para a cana-de-açúcar na região NorteExTO, contudo, como já destacado, esse resultado pode ser consequência da estratégia de distribuição do valor adicionado na SAM, atribuindo uma elevada produtividade marginal à irrigação nesta região. Excetuando-se as produções desta região, destacam-se os valores obtidos para o grupo de outras lavouras no Centro-Sul e NordesteTO, novamente como consequência dos efeitos positivos da adoção da irrigação nestas áreas.

A partir dos preços obtidos na solução numérica e da dotação dos fatores fixos, pode-se obter que o valor-sombra do montante de água utilizada nas lavouras em 2005 era de $\mathrm{R} \$ 3,1$ bilhões, a preços daquele ano, o que equivaleria a apenas 0,053\% daquele do capital físico da economia. A quase totalidade $(94,2 \%)$ do valor econômico da água, contudo, concentrar-se-ia nas atividades de rizicultura no Centro-Sul - localizada sobretudo no Rio Grande do Sul -, e na produção de outras lavouras no Centro-Sul e NordesteTO, refletindo o fato de que a adoção de regimes irrigados proporciona importantes ganhos de produtividade neste grupo.

Finalmente, devido às suas particularidades, o setor canavieiro apresenta pequena participação no valor total da água, mesmo sendo o maior usuário desta. Este aspecto sugere um uso ineficiente da água para suplementação hídrica no setor. A cobrança pelo uso da água, neste sentido, pode constituir importante incentivo ao uso mais eficiente deste recurso, mesmo que de maneira indireta, e que sua origem não seja a de corpos hídricos.

\section{CONCLUSÃO}

O Brasil possui uma das maiores disponibilidades hídricas do planeta, porém, distribuída desigualmente entre as regiões do país, o que limita seu uso nas atividades agrícolas e o 
fornecimento de água para áreas urbanas. Sendo a maior parcela da água retirada destinada à suplementação hídrica de lavouras, políticas de cobrança têm surgido visando criar incentivos para a utilização racional deste recurso, ao mesmo tempo em que se observa crescimento da área irrigada no país. Nestas políticas, por sua vez, há a necessidade de identificar os valores monetários associados à disposição a pagar dos agricultores e, então, determinar os valores a serem cobrados conforme objetivos específicos, que podem enfatizar a eficiência econômica ou mudanças na alocação de recursos.

Em sentido mais amplo, a incorporação de recursos naturais como fatores produtivos ainda é uma tarefa em andamento, especialmente nas estatísticas oficiais. Embora a estimação do estoque de capital físico das economias encontre-se relativamente sedimentada, valorações equivalentes para recursos naturais ainda se mostram incipientes, especialmente para os casos em que o recurso econômico não possui um mercado em que se forme um preço, como o que ocorre com a água utilizada nas técnicas de suplementação hídrica.

Neste contexto, o presente artigo buscou estimar o valor econômico da água a partir de sua relação teórica com o processo de acumulação de capital e crescimento econômico em um modelo de equilíbrio geral dinâmico, baseado em Roe et al. (2010), em que se permitiu uma abertura regional, de modo a enfatizar os diferentes contextos em que a irrigação ocorre no país. Este modelo foi calibrado por meio de uma matriz de contabilidade social, onde se desagregou a contribuição da água para a formação do valor adicionado, e de um exercício de decomposição do crescimento.

Os resultados enfatizam a importância dos diferentes graus de dinamismo nas atividades agrícolas, e do diferencial produtivo implicado pela passagem do sistema produtivo de sequeiro para irrigado como fonte de valor econômico da água, aspecto que se relaciona diretamente com as características regionais das produções. Dessa forma, a suplementação hídrica realizada de maneira pouco seletiva ou, no limite, apenas como forma de atender à legislação ambiental vigente, agrega pouco valor à produção comparativamente, por exemplo, à adoção destas técnicas almejando explicitamente aumentar a produtividade; essas situações têm paralelo, respectivamente, com as áreas canavieira e de fronteira agrícola no Brasil.

Do ponto de vista macroeconômico, cabe notar que o valor da água corresponde à parcela muito pequena do valor do estoque de capital físico brasileiro, o que seria esperado, tendo em conta a participação do valor adicionado da agricultura no valor adicionado total da economia, além da própria contribuição da água para a produção agrícola ser muito menor frente aos demais fatores de produção (capital, trabalho e terra).

Avanços na metodologia empregada contemplam desafios, como a consideração da água de origem pluvial ou estimação econométrica das elasticidades associadas às tecnologias de produção nas lavouras. A incorporação de modelos hidrológicos e/ou incorporação da degradação dos recursos naturais também são, em princípio, compatíveis com a abordagem adotada, embora constituam evidente desafio operacional. Os resultados poderiam ser afetados também por uma estrutura não constante do consumo de água pelos setores agrícolas, ainda que incorporada de maneira exógena. No caso particular da cana-de-açúcar, dada a legislação ambiental, a disponibilidade de água pode crescer em conjunto com a produção de etanol, exigindo modelagem específica. Finalmente, a versão do modelo utilizada ainda é estilizada, na medida em que o governo não é considerado como um agente em separado, tendo seu consumo incorporado ao das famílias. A presença de impostos ou subsídios explícitos afetaria a estrutura de incentivos, inclusive dos setores irrigantes, pondendo modificar os resultados, ainda que em pequena magnitude. 


\section{AGRADECIMENTOS}

Os autores agradecem à Coordenação de Aperfeiçoamento de Pessoal de Nível Superior (CAPES) pelo apoio financeiro à pesquisa realizada.

\section{REFERÊNCIAS}

Agência Nacional de Águas - ANA. (2017). Atlas irrigação: uso da água na agricultura irrigada. Brasília: ANA.

Agência Nacional de Águas - ANA. (2019). Manual de Usos Consuntivos da Água no Brasil. Brasília: ANA.

Aude, M. I. S. (1993). Estádios de desenvolvimento da cana-de-açúcar e suas relações com a produtividade. Ciência Rural, 23(2), 241-248. http://dx.doi.org/10.1590/S010384781993000200022.

Banco Mundial. (2019). World Development Indicators Database. Recuperado em 14 de maio de 2020, de https://databank.worldbank.org/data/source/world-development-indicators

Barbosa Filho, F. H., \& Pessôa, S. A. (2014). Pessoal ocupado e jornada de trabalho: uma releitura da evolução da produtividade no Brasil. Revista Brasileira de Economia, 68(2), 149-169. http://dx.doi.org/10.1590/S0034-71402014000200001

Barro, R. J., \& Sala-i-Martin, X. (2004). Economic growth (2nd ed.). Cambridge: MIT Press.

Bastos, A. C. (2013). Fornecimento de cana-de-açúcar e integração vertical no setor sucroenergético do Brasil (Dissertação de mestrado). Escola Superior de Agricultura "Luiz de Queiroz", Universidade de São Paulo, Piracicaba. http://dx.doi.org/10.11606/D.11.2013.tde-15052013094143.

Bragagnolo, C., Spolador, H. F. S., \& Barros, G. S. C. (2010). Regional Brazilian Agriculture TFP analysis: a stochastic frontier analysis approach. Economia, 11(4), 217-242. Recuperado em 14 de maio de 2020, de https://ideas.repec.org/a/anp/econom/v11y2010i4217_242.html

Brasil. Ministério da Integração Nacional. (2008). A irrigação no Brasil: situação e diretrizes. Brasília: IICA.

Companhia Ambiental do Estado de São Paulo - CETESB. (2015). Vinhaça - Critérios e procedimentos para aplicação no solo agrícola (3. ed.). São Paulo: CETESB.

Conesa, J. C., Kehoe, T. J., \& Ruhl, K. J. (2007). Modeling great depressions: the depression in Finland in the 1990s. Federal Reserve Bank of Minneapolis Quarterly Review, 31(1), 16-44. http://dx.doi.org/10.3386/w13591

Fang, X., Roe, T. L., \& Smith, R. B. W. (2015). Water shortages, intersectoral water allocation and economic growth: the case of China. China Agricultural Economic Review, 7(1), 2-26. http:// dx.doi.org/10.1108/CAER-02-2014-0014

Frizzone, J. A., Coelho, R. D., Dourado-Neto, D., \& Soliani, R. (1997). Linear programming model to optimize the water resource use in irrigation projects: an application to the Senator Nilo Coelho Project. Scientia Agricola, 54(spe), 136-148. http://dx.doi.org/10.1590/S010390161997000300016.

Fundação de Apoio à Universidade Federal de Viçosa - FUNARBE. (2011). Desenvolvimento de matriz de coeficientes técnicos para recursos hídricos no Brasil. Brasília: MMA. Recuperado em 14 de maio de 2020, de http://mma.gov.br/estruturas/161/_publicacao/161_ publicacao21032012055532.pdf 
Gasques, J. G., Bastos, E. T., Valdes, C., \& Bacchi, M. R. P. (2012). Produtividade da agricultura brasileira e os efeitos de algumas políticas. Revista de Política Agrícola, 21(3), 83-92. Recuperado em 14 de maio de 2020, de https://seer.sede.embrapa.br/index.php/RPA/ article/view/248/208

Gelain,J. G. (2018). Análise do custo-benefício da exportação de água virtual no setor agropecuário brasileiro (Dissertação de mestrado). Escola Superior de Agricultura "Luiz de Queiroz", Universidade de São Paulo. https://doi.org/10.11606/D.11.2018.tde-21062018-174459.

Haqiqi, I., Taheripour, F., Liu, J., \& van der Mensbrugghe, D. (2016). Introducing Irrigation Water into GTAP Data Base Version 9. Journal of Global Economic Analysis, 1(2), 116-155. http:// dx.doi.org/10.21642/JGEA.010203AF.

Horridge, M. (2003). ORANI-G: A Generic Single-Country Computable General Equilibrium Model. Australia: Monash University, Centre of Policy Studies.

Instituto Brasileiro de Geografia e Estatística - IBGE. (2019). Sistema IBGE de Recuperação Automática. Rio de Janeiro: IBGE. Recuperado em 14 de maio de 2020, de https://sidra. ibge.gov.br

Instituto de Pesquisa Econômica Aplicada - IPEADATA. (2019). Ipeadata. Recuperado em 14 de maio de 2020, de http://www.ipeadata.gov.br/

Johansson, R. C. (2005). Micro and macro-level approaches for assessing the value of irrigation water. Washington: World Bank. http://dx.doi.org/10.1596/1813-9450-3778.

Kelman, J., \& Ramos, M. (2005). Custo, valor e preço da água utilizada na agricultura. REGA Revista de Gestão de Água Da América Latina, 2(2), 39-48. Recuperado em 14 de maio de 2020, de https://www.abrh.org.br/SGCv3/index.php?PUB=2\&ID=66\&SUMARIO=821

Mulligan, C., \& Sala-i-Martin, X. (1991). A Note on the time-elimination method for solving recursive dynamic economic models (NBER Working Paper, No. t0116). Cambridge: NBER. http://dx.doi.org/10.3386/t0116.

Pinheiro, J. C. V., \& Shirota, R. (2000). Determinação do preço eficiente da água para irrigação no Projeto Curu-Paraipaba. Revista Economica do Nordeste, 31(1), 36-47.

Pinto, C. V. (2011). Effects of economy-wide factors on Brazilian economic growth and biofuels production: an inter-temporal general equilibrium analysis (Doctoral dissertation). College of Food, Agricultural and Natural Resource Sciences, University of Minnesota, Minnesota. Recuperado em 14 de maio de 2020, de http://hdl.handle.net/11299/104552

Ramsey, F. P. (1928). A mathematical theory of saving. Economic Journal (London), 38(152), 543. http://dx.doi.org/10.2307/2224098

Roe, T. L., \& Smith, R. B. W. (2015). Mainstreaming of ecosystem services into sectoral and macroeconomic policies and programmes of Republic of Kazakhstan. Nairóbi: UNEP.

Roe, T. L., Smith, R. B. W., \& Saracoğlu, D. S. (2010). Multisector growth models. USA: Springer. http://dx.doi.org/10.1007/978-0-387-77358-2

Santos, P. F. A., \& Spolador, H. F. S. (2018). Produtividade Setorial e Mudança Estrutural no Brasil - Uma Análise para o Período 1981 a 2013. Revista Brasileira de Economia, 72(2), 217-248. http://dx.doi.org/10.5935/0034-7140.20180011

Serviço Geológico do Brasil. (2019). Atlas Pluviométrico do Brasil. Recuperado em 14 de maio de 2020, de http://www.cprm.gov.br/publique/Hidrologia/Mapas-e-Publicacoes/AtlasPluviometrico-do-Brasil-1351.html 
Silva, M. A. S., Griebeler, N. P., \& Borges, L. C. (2007). Uso de vinhaça e impactos nas propriedades do solo e lençol freático. Revista Brasileira de Engenharia Agrícola e Ambiental, 11(1), 108114. http://dx.doi.org/10.1590/S1415-43662007000100014

Smith, R. B. W., \& Gemma, M. (2014). Valuing ecosystem services in macroeconomic settings. In P. Nunes, P. Kumar, \& T. Dedeurwaerdere (Eds.), Handbook on the economics of ecosystem services and biodiversity (pp. 130-152). United Kingdom: Edward Elgar Publishing. http:// dx.doi.org/10.4337/9781781951514.00015

Smith, R. B. W., Nelson, H., \& Roe, T. L. (2015). Groundwater and Economic Dynamics, Shadow Rents and Shadow Prices: The Punjab. Water Economics and Policy, 1(3), 1550014. http:// dx.doi.org/10.1142/S2382624X15500149

Teixeira, R. M. (1990). Demanda de água: a tarifa vista sob a ótica do preço-sombra (Dissertação de mestrado). Escola de Pós Graduação em Economia, Fundação Getúlio Vargas, São Paulo. Recuperado em 14 de maio de 2020, de http://hdl.handle.net/10438/7962

Torres, M. D. O., Maneta, M., Howitt, R., Vosti, S. A., Wallender, W. W., Bassoi, L. H., \& Rodrigues, L. N. (2012). Economic impacts of regional water scarcity in the São Francisco River Basin, Brazil: an application of a linked hydro-economic model. Environment and Development Economics, 17(2), 227-248. http://dx.doi.org/10.1017/S1355770X11000362

Tsur, Y., Dinar, A., Doukkali, R. M., \& Roe, T. (2004). Irrigation water pricing: policy implications based on international comparison. Environment and Development Economics, 9(6), 735755. http://dx.doi.org/10.1017/S1355770X04001494

União da Indústria de Cana-de-Açúcar - UNICA. (2019). Mapa da produção. São Paulo: UNICA. Recuperado em 14 de maio de 2020, de https://www.unica.com.br/setor-sucroenergetico/ mapa-da-producao/ 